\title{
Management Response to Online Review: The Case of Hong Kong Luxury Hotels
}

\author{
Suki Siuki Tam ${ }^{1}$, Lawrence Hoc Nang Fong ${ }^{2(\bowtie)}(\mathbb{D})$, \\ and Rob $\mathrm{Law}^{2,3}$ \\ 1 School of Hotel and Tourism Management, \\ The Hong Kong Polytechnic University, Hong Kong S.A.R., China \\ ${ }^{2}$ Department of Integrated Resort and Tourism Management, \\ Faculty of Business Administration, University of Macau, Macau S.A.R., China \\ \{lawencefong, roblaw\}@um.edu.mo \\ 3 Asia-Pacific Academy of Economics and Management, \\ Department of Integrated Resort and Tourism Management, \\ Faculty of Business Administration, University of Macau, Macau S.A.R., China
}

\begin{abstract}
Electronic word-of-mouth (eWOM) is regarded as crucial in business development. Given the intangible nature of tourism and hospitality products, potential customers find it hard to assess them before making purchase. Accordingly, online customer reviews and management responses have influential roles in their decision-making process. While a plethora of previous research focused on customer reviews, scholarly attention on how luxury hotels respond to the reviews was scant. Using content analysis, this study examines the management response characteristics of 35 luxury hotels and response style of 7 luxury chain hotels in Hong Kong. Their response characteristics including response frequency, responder's job position, and timeliness of response were generally similar. The response style and tone (professional and conversational tones) vary with hotels even they are in the same hotel group. Implications on practice of management responses are offered for luxury hotel operators.
\end{abstract}

Keywords: Communication style $\cdot$ Hotel $\cdot$ Online review $\cdot$ eWOM

\section{Introduction}

The Internet is an essential platform for industry practitioners to communicate with customers and enables the practitioners to expand the market segment as well as to retain the customers [1]. As experiencing a service before making purchase is difficult for customers, they would be more concerned about the recommendation from various online sources, such as other customers, experts, and key opinion leaders; however, the impacts of online recommendation sources on consumer decision making vary [2]. This situation is particularly relevant to tourism and hospitality products because of their intangible nature and the boom of tourism and hospitality online review platforms, for examples, TripAdvisor, Ctrip, and others. These platforms power the spread of wordof-mouth among consumers and have become a crucial factor for making purchase decision [3]. 
The usual reasons for customers to write reviews revolve around customer satisfaction in consequence of performance-expectation comparison, desirability for service recovery, and seeking social support. From the organizational perspective, a positive review reinforces online reputation and consequently enhances hotel occupancy rate and financial performance [4]. As online reviews can influence hotel reputation and consumer decisions, hotels need to effectively manage the online reviews through their online responses which are publicly available on the review platforms. Management response is mandatory if the review is negative, emotional, and characterized by customer expectation of improvement [5]. In management response, the responder's job position and timeliness of response are the major factors for assessing hotel performance. Apart from these characteristics, the response contents and tone are also considered. Therefore, hotels need to deliberate their responses in terms of suitability [6]. Scholars have provided recommendations on the structure of responses (i.e., what should be mentioned), and the responder's tone (i.e., how to present responses) [7-9]. Practitioners also put emphasis on management responses. TripAdvisor provides response guidelines for hoteliers and encourages them to respond to each review [10].

Prior research has provided significant implications on effective ways to respond to customer reviews in hospitality $[6,11]$. However, the implications may not be applicable to all types of hotels as their customers' expectations vary. Empirical evidence drawn from specific types of hotels will extend knowledge in the existing literature and equip relevant practitioners with accurate implications. While expectation for luxury hotels is generally higher than that for hotels of lower class, management response is a mandatory practice. It should be important for luxury hotel operators to understand what their peers are doing and how they can improve in responding to their customers. Therefore, focusing on Hong Kong which is a popular destination in the world, this study collected luxury hotels' management responses from TripAdvisor, contentanalyzed the data, synthesized the response characteristics and style, and provided implications for the practitioners.

\section{Literature Review}

Electronic word-of-mouth (eWOM) is currently considered as the most important source of information which helps customers make purchase decisions. In hospitality and tourism, interpersonal influence is essential because the products are intangible and inaccessible before consumption. Rapid development of the Internet facilitates people to share and exchange information using different types of electronic media, such as email, blogs, websites, chatrooms, and newsgroups. In hospitality and tourism, managing eWOM is an indispensable marketing strategy to achieve two purposes: (1) information generation and (2) revenue generation. Collected information can be used for product improvement, reputation reinforcement, and customer relationship management. Financial performance would eventually be enhanced [3]. Suppliers' unethical practice of employing fake review writers reflects the importance of online reviews in determining their business performance [12].

Numerous websites allow users to share their hotel experience after consumption. Intuitively speaking, positive reviews motivate users to make bookings, whereas 
negative reviews discourage bookings. In addition to the review contents, the person who writes the review influences users' evaluation of the service providers. Chan, Lam, Chow, Fong, and Law [13] revealed that demographic and preference similarities between readers and reviewers affect the influence of the review valence on hotel booking intention. Readers tend to deeply consider reviews provided by people with a similar background, such as age, occupation, country of origin, and username, because they seem to share common judgment. As such, information source is an important factor that potential customers would consider [14]. Following this rationale, when they read the management responses, users would pay attention to the person who writes the response, especially the responder's job level.

Apart from job level, users would also consider other characteristics of management response such as responding time, response contents, style, and tone [6]. As timely response to customers' comments is important [15], reviewers expect hoteliers to give a speedy response related to the service failure they described in the reviews. Responding time would affect customer satisfaction and repurchase intention [16]. In addition, speedy response to negative online review effectively improves customer trustworthiness with the hotels [8]. Trust will eventually be translated into better financial performance of the hotels [6]. Regarding response content, some elements are necessary and important. Cook [17] indicated that in handling complaints, an effective resolution letter should express appreciation for the customer's opinion, apologize for inconvenience, acknowledge the problems, explain findings from investigation, offer compensation, and present a resolution plan.

Organizations should ensure that a message is presented properly and with a suitable tone. From the customers' perspective, acknowledging a problem is a rapportenhancing move which is frequently applied in effective responses, whereas denying a problem is a rapport-damaging move [18]. When facing an unfair review, a defensive managerial response strategy is needed to protect the reputation of service providers. However, the defensive message should also be communicated in a professional tone [19].

Based on our literature review, response characteristics and style of luxury hotels are under-researched. This gap is filled by the current study using the method which is articulated in the next section.

\section{Method}

Using a qualitative approach which has been widely adopted in previous hospitality and tourism research [20], this study content-analyzed the management responses made by luxury hotels in Hong Kong. Data were collected from TripAdvisor.com which is a highly popular online review website that allows customers to share their tourism and hotel experiences. As our targets are luxury hotels, all Hong Kong hotels which were classified as 5-star by TripAdvisor were selected - 35 hotels. Data collection and analysis were separated into two parts. The first part analyzed response characteristics (presence of response, responder's job level, and responding time) based on a large volume of data. The second part which concerns the response style and tone requires a 
deeper analysis was conducted manually and seven hotels were included. To rule out any possible bias caused by the language, this study only focused on English reviews.

In the first part, TripAdvisor reviews, regardless of their valence, posted in the recent three years (2018-2020) were retrieved. Recent reviews allow the reveal of latest practices in the industry. Although this period featured the non-existence and existence of COVID-19, the impact of pandemic is unlikely to be a concern as this study does not focus on specific issues (e.g., safety of operation), but rather focuses on fundamental components including responder's job position and responding time. A total of 109,903 reviews were analyzed in this study. First, we recorded if the reviews have any management response. Second, if there was a response, two response characteristics including responder's job position and responding time were recorded.

The second part of this research focused on the response style and tone. As noted earlier, selected hotels are included in this part. Our selection was based on whether a hotel is a chain hotel. Compared with independent hotels, chain hotels are supposed to possess richer experience and more resources in dealing with customers. The system and procedures in chain hotels are generally more well-established, enabling them to better satisfy their customers [21]. Because of their operation in different cities and countries, chain hotels may also be more capable in responding to customers with different cultural backgrounds. Therefore, chain hotels practice should have high reference value for luxury hotel operators. Furthermore, while chain hotels belong to the same group, they may need to maintain a certain level of consistency in their operations. Then, their response style and tone may be similar to their peers in the same group. This conjecture, however, had not been examined in previous studies yet and was examined in this study.

This study selected seven hotels from three hotel chains, including (1) Hyatt Regency Hong Kong Sha Tin and (2) Grand Hyatt Hong Kong from the Hyatt Group; (3) Kowloon Shangri-La Hong Kong, (4) Island Shangri-La Hong Kong, and (5) Kerry Hotel Hong Kong from the Shangri-la Group; and (6) Regal Hong Kong Hotel and (7) Regal Airport Hotel from the Regal Group. Given the large scale of available data, only responses written in 2020 were extracted. A total of 1,264 managerial responses were collected. The comments and feedback were read word-by-word to ensure accurate interpretation of the content. Any inconsistent interpretations of the investigators were resolved by discussion until consensus was achieved. Review valence including positive, neutral, and negative were also recorded.

\section{Findings and Discussion}

\subsection{Characteristics of Management Responses}

Among the 35 luxury hotels, 19 responded to every review regardless of valence. Although other hotels did not respond to all reviews, they generally addressed most of the reviews. The findings are consistent with a previous study which interviewed 13 managers [22] and found that most managers openly responded to online positive and negative reviews. A few of them privately contact the customers who posted negative reviews. Only one manager did not respond to customer comments, and that manager 
believed that problems should be fixed before the customer leaves the hotel and that post-service recovery is useless in enhancing customer satisfaction. While all hotels in this study were luxury hotels, people would have a high expectation on the service. Responding to all reviews gives an impression that the hotels value and care every customer. Responding to negative reviews is essential as any ignorance will trigger people's doubt on the hotel's service standard. While potential customers make decision based on the reviews and responses [14], a well-written management response may help transform readers to customers. On the other hand, responding to positive reviews is a kind of appreciation which is a practice in line with the spirit of hospitality. Therefore, responding to all reviews should be the best practice for luxury hotels. Despite this, the responses should be carefully written because inappropriate responses to an online review can be disastrous [22].

By observing the responder's job titles, all feedback was endorsed by staff at the management level. Some examples were general manager, director of rooms, and director of guest relations. Responder's organizational position can have an influence on customer satisfaction [7]. Response from someone at management level shows respect to the customers. This practice is especially important in dealing with negative online reviews because the complainants may want the management to be aware of the service failure they had encountered in the hotel. Prior research reported that changing customer attitude should be handled by a credible person [8]. In this regard, compared with operational staff, management staff should have advantage. However, whether the responses should be made by the general manager is controversial. While the job title in the response implies it is that person who responds to the review, customers and users would question if it is really the general manager who is supposed to deal with strategic issues to write the response. In this case, credibility of the hotel will be threatened. Then, the job title effect will backfire.

The analysis shows that most hotels (26 out of 35 ) responded to reviews within a week. According to the findings about response time to complaints [16], customers deem a response made within 7.9 days as acceptable. In this sense, the hotels in this study generally performed well in timeliness. Timely response should be expected by most (if not all) customers, especially those who raised complaints in the reviews. This expectation should be exceptionally high for luxury hotels as they are supposed to outperform the low-class counterparts in all service aspects. A delayed reaction or service recovery would threaten the reputation of service provider [23]. Complainants would consider timely response as something which a service provider should prioritize because their feeling of uncertainty and negative emotion need to be promptly addressed [24]. Therefore, it was even argued that additional compensation is not necessarily more important than timely response in addressing a complaint [25].

\subsection{Response Style and Tone}

Our perusal of management responses made by the seven chain hotels revealed that repetition of contents in customer review was salient in positive reviews but not in negative reviews. The hotels might not want to reinforce the incidence or service failure in their response to negative reviews. They generally acknowledged the problems and expressed apologies. In contrast, when responding to compliments in positive reviews, 
the hotels might want users to pay attention to their good deeds. It may also be due to the fact that not much can be written to address compliments. It is worth-noting that lengthy responses demonstrate hotel's serious attitudes toward consumer feedback and enhances customer satisfaction [6]. Therefore, repetition of the compliments is a viable approach. Furthermore, we found that repetition of contents is frequent if hotel staff is praised. This is important as hotel is a service industry where staff is the most valuable capital.

Regarding the contents in responses to positive review, responders generally included structural components suggested in previous studies which are greeting, expressing feelings, thanking reviewers, and continuing relationships, with some of them also recognizing the reviewer's value $[9,18,26]$. However, when facing customer complaints, their response style exhibited some variations. This approach is important as personalized responses help regain customers' trustworthiness [27]. The personalized messages signal the hotel's concerns about the customer's opinions and the high level of hotel engagement [28]. Therefore, in the case of service recovery, management response should not be standardized [29].

Response tone can generally be categorized into conversational tone and professional tone. A conversional tone refers to an engaging and natural style of organizational communication as perceived by consumers [30]. Conversely, professional tone means a relatively standard response which is more respectful, formal, and factsoriented [8]. An example of response consistent with professional tone is shown below:

"Thank you for taking your precious time to share your experience at Grand Hyatt Hong Kong.

We are most delighted to hear that you enjoyed your stay in a room with stunning view of the harbor, and the exceptional service provided by Osman, Grace, and our Guest Experience Team has enhanced the experience. We will definitely pass on your kind words of praise to the team to recognize their efforts. Your compliments on our scrumptious breakfast spread is also much appreciated.

Thank you for your perfect rating and we look forward to welcoming you back in the nearest future". [ 31 ]

In this example, it can be observed that the writing is formal and contains respectful words such as "thank you" and "much appreciated". The response also emphasizes on the facts which the customer appreciated, for examples, "stunning view", "exceptional service", and "scrumptious breakfast spread".

The following shows an example of response featuring conversational tone:

"Firstly, thank you for staying at Kowloon Shangri-La, Hong Kong for having taken the time to share your feedback with us.

Please accept my sincerest apologies for the inconveniences that you have experienced regarding your room reservation. I have personally reviewed the whole situation as described with my Reservations Manager. I concurred with you that you should expect nothing but a good experience throughout the reservation process, especially being our loyal guests. Please rest assured that we are able to make necessary improvements to enhance our guest's booking experience. 
Despite of this matter, l am very thrilled to know that we provided you with an enjoyable stay with us.

Indeed, it's always our pleasure to take care of you. Thank you very much for your compliments about the Hotel and our friendly services. We are looking forward to welcoming you back at the Hotel again real soon" [ 32 ].

In this example, the tone is relatively less formal, such as the phrases "firstly", "I am very thrilled", and "it's". The third and fourth paragraphs of this response sound natural as of s/he was talking to the guest. This communication style was recommended when customer reviews are negative because it is beneficial for organizational reputation [33]. The natural style of communication helps shorten the psychological distance between the hotel and guest, which will in turn increase the effectiveness of service recovery [34].

As this study also investigates whether chain hotels within the group had different response styles and tones, we observed if variations exist during our analysis of the data. We found that the tone used by hotels in Hyatt group and Regal group was consistent. They commonly used a professional tone in responding to positive or negative customer reviews. However, hotels in Shangri-la group adopted both professional and conversational tone approaches. The adopted approaches seem varying with the responders. We found that two managers were assigned to respond to online customer reviews. The resident manager preferred using a conversational tone in responding to all types of reviews. In contrast, the general manager preferred using a professional tone, especially in responding to positive and neutral reviews. The findings echo the argument that communication styles vary with the socio-demographic background of responders [35]. While general manager is at the executive level of the organization, a professional (formal) tone should be coherent with his/her status. Responder at the middle management level (e.g., resident manager) should be more suitable to use conversational tone.

Regarding response contents, hotels in the same group generally adopted similar structure components including greeting, expressing feelings, thanking reviewers, and continuing relationships, in responses to positive reviews. However, there were also exceptions. Regal Hong Kong Hotel preferred to use similar sentences to respond to every positive reviews. However, Regal Airport Hotel managers employed varied words to respond. On the other hand, more variations between chain hotels in the same group were observed in responses to negative reviews. Grand Hyatt Hong Kong preferred to explain the cause of the problem and was self-justifying in responding to problems that were not caused by the hotel. Conversely, Hyatt Regency Hong Kong Sha Tin would not mention problems in detail or offer explanations but instead directly apologizes for any inconvenience caused.

According to Ho [18], acknowledging problems helps maintain relationships with customers and is the most effective way to reduce customer dissatisfaction. Denying a problem should be avoided in the situation of service failure. Surprisingly, we found that these practices were not consistently pursued. Kowloon Shangri-la Hong Kong tended to respond to negative reviews by acknowledging the problems, whereas Island Shangri-la Hong Kong tended not to mention the problems stated in the customer review while neither acknowledged nor denied the problems. Additionally, they 
typically used similar content to respond to negative reviews. Kerry Hotel Hong Kong made relatively brief responses. Although it was willing to admit the problems, it seldom expressed apologies. The findings show that the chain hotels in the same group did not use a consistent approach.

\section{Contributions and Managerial Implications}

Online reviews and management responses are both important in influencing customer decision making and hotel performance, therefore hotels should devote effort to manage eWOM. In view of the high service standard of luxury hotels, useful insights can plausibly be drawn from their responses. While scholarly attention on luxury hotel management response was scarce, the current research fills the gap by unveiling the response characteristics, style, and tone of this hotel class, so that a comprehensive theoretical framework can be developed in the future.

Findings of this study show that most hotels responded to all review regardless of the review valence. This practice should be strictly followed by other luxury hotels as response hints that the hotels value and care their customers. In general, the responses were made within a week which can be a benchmark for luxury hotels in determining the performance indicators of the team responsible for managing customer reviews. As customers generally expect a prompt response, hotels should strive to respond even quicker but without sacrificing any accuracy. The findings show that responders' job positions were primarily at the management level. This industry norm signals that luxury hotels should not assign an operational staff to respond to the customers. Otherwise, customers might feel disrespectful.

Regarding the response style, professional and conversational tones were used. However, if the review was negative, a conversational tone was salient while message was personalized. These practices appear reasonable as a conversational tone helps shorten the psychological distance between the guest and hotel, while personalized message demonstrates hotel's sincerity in addressing the customers' problems. This approach is worthwhile for other luxury hotels to follow. On the other hand, the findings generally conclude that chain hotels in the same group adopted different response styles and tones. The appropriateness of inconsistency approach is controversial. Customers may expect consistent service from hotels in the same group. This expectation may be more salient for frequent customers and those who have joined the membership of the hotel group. The group may need to provide guidelines for its hotels in their response to online reviews.

\section{Limitations and Future Research}

This study has some limitations. First, while a qualitative approach was adopted, we have to ensure a manageable data size. So, only recent reviews of a small number of hotels were analyzed. Robustness of the findings was threatened. Future research is recommended to adopt a quantitative approach such as big data analytics. Given the findings of this exploratory study, hypotheses can be developed and validated in the 
future, for instance, the impact of a response on subsequent reviews and the impact of review topics (e.g., safety issues) on management responses. Second, to reduce any language bias, only English reviews and responses were analyzed. We do not know if language would make a difference on the findings. Third, this study only considered hotels in Hong Kong. Findings may be different if the case was from other places. Given these limitations, future research is recommended to enlarge the sample size, incorporate non-English reviews, and focus on hotels in other regions and countries. Comparisons can also be made between English and non-English reviews (and responses), and responses made by chain hotels located in different regions and countries, as well as responses made by chain hotels versus independent 5-star hotels. Succeeding studies can examine if and how the socio-demographic background of responder influences the responses, especially if the responses are personalized. Another interesting future study would be whether responders' names (Chinese versus non-Chinese) would affect user's evaluation of responses. Although the findings and implications were drawn from the practices of luxury hotels, it does not mean that their practices are the best. Future research should evaluate the responses using primary research approach, for example, survey, experiment, and even mixed-method approach so that broader and deeper insights can be drawn.

Acknowledgement. This project was partly supported by a research grant funded by the University of Macau (Ref.: CPG2021-00036-APAEM).

\section{References}

1. Osenton T (2002) Customer share marketing: how the world's great marketers unlock profits from customer loyalty. FT Press, New Jersey

2. Senecal S, Nantel J (2004) The influence of online product recommendations on consumers' online choices. J Retail 80:159-169. https://doi.org/10.1016/j.jretai.2004.04.001

3. Litvin SW, Goldsmith RE, Pan B (2008) Electronic word-of-mouth in hospitality and tourism management. Tour Manag 29:458-468. https://doi.org/10.1016/j.tourman.2007.05. 011

4. Diéguez-soto J, Fernández-gámez MA, Sánchez-marín G (2017) Family involvement and hotel online reputation. BRQ Bus Res Q 20:151-163. https://doi.org/10.1016/j.brq.2017.05. 001

5. Xu X (2020) Examining consumer emotion and behavior in online reviews of hotels when expecting managerial response. Int J Hosp Manag 89:102559. https://doi.org/10.1016/j.jhhm. 2020.102559

6. Xie KL, So KKF, Wang W (2017) Joint effects of management responses and online reviews on hotel financial performance: a data-analytics approach. Int J Hosp Manag 62:101-110. https://doi.org/10.1016/j.ijhm.2016.12.004

7. Min H, Lim Y, Magnini VP (2015) Factors affecting customer satisfaction in responses to negative online hotel reviews: the impact of empathy, paraphrasing, and speed. Cornell Hosp Q 56:223-231. https://doi.org/10.1177/1938965514560014

8. Sparks B, So K, Bradley G (2016) Responding to negative online reviews: the effects of hotel responses on customer inferences of trust and concern. Tour Manag 53:74-85. https:// doi.org/10.1016/j.tourman.2015.09.011 
9. Zhang Y, Va'squez C, (2014) Hotels' responses to online reviews: managing consumer dissatisfaction. Discourse Context Media 6:54-64. https://doi.org/10.1016/j.dcm.2014.08. 004

10. Tripadvisor. https://www.tripadvisor.com/TripAdvisorInsights/w805

11. Li C, Cui G, Peng L (2017) The signaling effect of management response in engaging customers: a study of the hotel industry. Tour Manag 62:42-53. https://doi.org/10.1016/j. tourman.2017.03.009

12. Li L, Lee KY, Lee M, Yang SB (2020) Unveiling the cloak of deviance: linguistic cues for psychological processes in fake online reviews. Int J Hosp Manag 87:102468. https://doi. org/10.1016/j.ijhm.2020.102468

13. Chan ICC, Lam LW, Chow CWC, Fong LHN, Law R (2017) The effect of online reviews on hotel booking intention: the role of reader-reviewer similarity. Int J Hosp Manag 66:54-65. https://doi.org/10.1016/j.ijhm.2017.06.007

14. Sparks BA, Perkins HE, Buckley R (2013) Online travel reviews as persuasive communication: the effects of content type, source, and certification logos on consumer behavior. Tour Manag 39:1-9. https://doi.org/10.1016/j.tourman.2013.03.007

15. Hart C, Heskett JL, Sasser W (1990) The profitable art of service recovery. Harv Bus Rev 68:148-156

16. Mattila AS, Mount DJ (2003) The impact of selected customer characteristics and response time on E-complaint satisfaction and return intent. Int J Hosp Manag 22:135-145. https:// doi.org/10.1016/S0278-4319(03)00014-8

17. Cook S (2012) Complaint management excellence: Creating customer loyalty through service recovery. Kogan Page Limited, United Kingdom

18. Ho V (2018) Exploring the effectiveness of hotel management's responses to negative online comments. Lingua 216:47-63. https://doi.org/10.1016/j.lingua.2018.10.004

19. Surachartkumtonkun J, Grace D, Ross M (2021) Unfair customer reviews: third-party perceptions and managerial responses. J Bus Res 132:631-640. https://doi.org/10.1016/j. jbusres.2020.09.071

20. Sandiford PJ, Seymour D (2007) A discussion of qualitative data analysis in hospitality research with examples from an ethnography of English public houses. Int J Hosp Manag 26:724-742. https://doi.org/10.1016/j.ijhm.2006.05.002

21. Moreno-perdigón MC, Guzmán-pérez B, Mesa TR (2021) Guest satisfaction in independent and affiliated to chain hotels. Int J Hosp Manag 94:102812. https://doi.org/10.1016/j.ijhm. 2020.102812

22. Chen YF, Law R, Yan KK (2016) Managing negative electronic word of mouth (eWOM) from the perspective of luxury hotel managers. e-Rev Tour Res. 7: http:// 3ws1wk1wkqsk36zmd6ocne81.wpengine.netdna-cdn.com/files/2016/01/ENTER2016_ submission_166.pdf

23. Hogreve J, Bilstein N, Mandl L (2017) Unveiling the recovery time zone of tolerance: when time matters in service recovery. J Acad Mark Sci 45(6):866-883. https://doi.org/10.1007/ s11747-017-0544-7

24. Xu Y, Li H, Law R, Zhang Z (2020) Can receiving managerial responses induce more user reviewing effort? a mixed method investigation in hotel industry. Tour Manag 77:103982. https://doi.org/10.1016/j.tourman.2019.103982

25. Liu H, Jayawardhena C, Dibb S, Ranaweera C (2019) Examining the trade-off between compensation and promptness in eWOM-triggered service recovery: a restorative justice perspective. Tour Manag 75:381-392. https://doi.org/10.1016/j.tourman.2019.05.008 
26. Ascaniis SD, Borrè A, Marchiori E, Cantoni L (2015) Listen to your customers! how hotels manage online travel reviews. The case of hotels in Lugano. In: Tussyadiah I, Inversini A (eds) Information and communication technologies in tourism 2015. Springer, Cham, pp 5972. https://doi.org/10.1007/978-3-319-14343-9_5

27. Zheng T, Youn H, Kincaid CS (2009) An analysis of customers' e-complaints for luxury resort properties. J Hosp Mark 18:718-729. https://doi.org/10.1080/19368620903170240

28. Wei W, Miao L, Huang ZJ (2013) Customer engagement behaviors and hotel responses. Int J Hosp Manag 33:316-330. https://doi.org/10.1016/j.ijhm.2012.10.002

29. Li C, Cui G, Peng L (2018) Tailoring management response to negative reviews: the effectiveness of accommodative versus defensive responses. Comput Hum Behav 84:272284. https://doi.org/10.1016/j.chb.2018.03.009

30. Kelleher T (2009) Conversational voice, communicated commitment, and public relations outcomes in interactive online communications. J Commun 59:172-188. https://doi.org/10. 1111/j.1460-2466.2008.01410.x

31. TripAdvisor. https://www.tripadvisor.com/ShowUserReviews-g294217-d305392-r7768679 13-Grand_Hyatt_Hong_Kong-Hong_Kong.html

32. TripAdvisor. https://www.tripadvisor.com/ShowUserReviews-g294217-d302133-r7503950 78-Kowloon_Shangri_La_Hong_Kong-Hong_Kong.html

33. Crijns H, Cauberghe V, Hudders L, Claeys AS (2017) How to deal with online consumer comments during a crisis? the impact of personalized organizational responses on organizational reputation. Comput Hum Behav 75:619-631. https://doi.org/10.1016/j.chb. 2017.05.046

34. Lii YS, Pant A, Lee M (2012) Balancing the scales: recovering from service failures depends on the psychological distance of consumers. Serv Ind J 32:1775-1790. https://doi.org/10. 1080/02642069.2011.575130

35. Beydilli ET, Kurt M (2020) Comparison of management styles of local and foreign hotel chains in Turkey: a cultural perspective. Tour Manag 79:104018. https://doi.org/10.1016/j. tourman.2019.104018

Open Access This chapter is licensed under the terms of the Creative Commons Attribution 4.0 International License (http://creativecommons.org/licenses/by/4.0/), which permits use, sharing, adaptation, distribution and reproduction in any medium or format, as long as you give appropriate credit to the original author(s) and the source, provide a link to the Creative Commons license and indicate if changes were made.

The images or other third party material in this chapter are included in the chapter's Creative Commons license, unless indicated otherwise in a credit line to the material. If material is not included in the chapter's Creative Commons license and your intended use is not permitted by statutory regulation or exceeds the permitted use, you will need to obtain permission directly from the copyright holder.

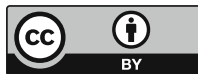

